\title{
Involvement of Renin-Angiotensin System in Damage of Angiotensin- Converting Enzyme Inhibitor Captopril on Bone of Normal Mice
}

\author{
Jin-Xin Liu, ${ }^{a, \#}$ Liang Wang, ${ }^{b, \#}$ and Yan Zhang*,a \\ ${ }^{a}$ Center for Systems Biomedical Sciences, University of Shanghai for Science and Technology; Shanghai 200093, P. R. \\ China: and ${ }^{b}$ Department of Orthopaedics, The 309th Hospital of Chinese People's Liberation Army; Beijing 100091, \\ P. R. China.
}

Received December 6, 2014; accepted March 5, 2015

\begin{abstract}
This study was performed to investigate the effect of angiotensin-converting enzyme inhibitor, captopril, on bone metabolism and histology, and the action of captopril on the components of the skeletal reninangiotensin system (RAS) and bradykinin receptor in normal male mice. The mice were orally administered captopril $(10 \mathrm{mg} / \mathrm{kg})$ for 4 weeks with vehicle-treated mice as normal control. The histology of trabecular bone at the distal femoral end was determined by hematoxylin \& eosin, Safranin $O$ and Masson-Trichrome staining. The captopril-treated mice showed a decreased level of testosterone $(p<0.05)$ and procollagen type I N-terminal propeptide $(p<0.05)$ in serum as compared to those in the control group. Captopril has detrimental effects on trabecular bone as demonstrated by the loss of cancellous bone mass and network connections as well as changes to the chondrocytes zone. The expression of angiotensin-converting enzyme $(p<0.05)$, renin receptor $(p<0.01)$, angiotensin II $(p<0.05)$ and bradykinin receptor $2(p<0.05)$ was significantly up-regulated following the captopril treatment. Thus, the potential underlying mechanism of the damage of captopril on bone can be attributed the increased activity of local bone RAS and the activation of bradykinin receptor.
\end{abstract}

Key words renin-angiotensin system; bradykinin receptor; captopril; bone

The renin-angiotensin system (RAS) is a hormonal cascade that is thought to act as a master controller of blood pressure and fluid balance within the body. ${ }^{1)}$ In addition to the systemic RAS, there is a fully functional RAS in local tissue, which is postulated to participate in various physiological and pathological processes such as insulin secretion, ${ }^{2)}$ glomerular sclerosis,${ }^{3)}$ renal inflammation, ${ }^{4)}$ atherosclerosis, ${ }^{5)}$ and cardiac hypertrophy. ${ }^{\text {) }}$

Recent in vivo studies showed that the components of RAS, such as renin, angiotensin-converting enzyme (ACE), and angiotensin II (Ang II) receptors, were expressed in the local milieu of bone, ${ }^{7-10)}$ and in vitro study identified the expression of Ang II receptors in primary osteoblasts derived from newborn mouse calvaria, ${ }^{7)}$ indicating the components of RAS are expressed locally in bone microenvironment. Our further animal studies demonstrated that the local RAS in bone was involved in age-related osteoporosis of aging mice, ${ }^{11)}$ and bone deteriorations of mice with either obstructive nephropathy ${ }^{12)}$ or type 1 diabetes. ${ }^{13)}$ Other groups elucidated the involvement of skeletal RAS in the process of fracture healing in a mouse femur fracture model, ${ }^{14)}$ and the steroid-induced osteonecrosis in rabbits ${ }^{10)}$ as well as the development of postmenopausal osteoporosis in ovariectomized (OVX) animal models ${ }^{15,16)}$ and glucocorticoid-induced osteoporosis. ${ }^{9)}$ Therefore, it concludes that the local RAS exists in bone tissue and plays an important role in local bone metabolism.

The main effector peptide Ang II in RAS is formed from angiotensin I by the action of ACE, a key molecule in this system. Patients treated with an ACE inhibitor (ACEI) showed an increased bone mineral density (BMD) and a reduced fracture risk. ${ }^{17-19)}$ However, recent clinical data indicated that the use

\footnotetext{
\# These authors contributed equally to this work.

* To whom correspondence should be addressed. e-mail: medicineyan@aliyun.com
}

of ACEI did not have beneficial effects on bones, ${ }^{20)}$ and even led to bone loss in older American men, ${ }^{21)}$ Chinese women ${ }^{22)}$ and Japanese. ${ }^{23)}$

In animal studies, the treatment with ACEI attenuated ovariectomy-induced decrease in bone density, ${ }^{24)}$ accelerated bone healing and remodeling in a murine femur fracture mode, ${ }^{14)}$ and improved osteoporosis and hypertension in Tsukuba hypertensive mice. ${ }^{7)}$ While, our recent study elucidated that the treatment with ACEI, captopril $(10 \mathrm{mg} / \mathrm{kg}$, intragastrically (i.g.)), significantly elevated serum level of tartrate-resistant acid phosphatase, and had a trend to decrease bone mineral density of trabecular bone and damage microarchitecture of proximal tibial head and distal femoral end in type 1 diabetic mice. ${ }^{13)}$

In view of the contradictory effects of ACEI on bone health from human and animal studies, we are keen to know the effects of ACEI on bone tissue of normal mice. Thus, this study was performed to investigate the effect of ACEI, captopril, on bone histology and the action of captopril on the components of skeletal RAS in normal male mice.

\section{MATERIALS AND METHODS}

Animal Treatment Ten-week-old male ICR mice (Slac Laboratory Animal, Shanghai, China) were allowed to acclimate to their environment for 1 week before drug treatment. The mice were randomly divided into normal control group $(n=7)$ and captopril-treated group $(10 \mathrm{mg} / \mathrm{kg}$, i.g., $n=8)$. Four weeks after drug administration, spot urine of each mouse was collected. Serum, tibias and femurs were immediately harvested for a variety of biochemical, histological and molecular analyses. In addition, the mice tibias were collected after the treatment with captopril for 8 weeks. The animal 
Table 1. Chemistries in Serum and Urine

\begin{tabular}{lcccc}
\hline \hline & Serum Ca $(\mathrm{mg} / \mathrm{dL})$ & Serum P $(\mathrm{mg} / \mathrm{dL})$ & Urine $\mathrm{Ca} / \mathrm{Cr}(\mathrm{mg} / \mathrm{mg})$ & Urine P/Cr $(\mathrm{mg} / \mathrm{mg})$ \\
\hline Control & $9.65 \pm 0.11$ & $8.28 \pm 0.49$ & $0.259 \pm 0.142$ & $0.306 \pm 0.103$ \\
Captopril & $9.92 \pm 0.15$ & $7.15 \pm 0.34$ & $0.207 \pm 0.058$ & $0.740 \pm 0.202$ \\
\hline
\end{tabular}

Values are expressed as means \pm S.E.M., $n=7-8$ in either group. Ca, calcium; Cr, creatinine; P, phosphorus.

Table 2. Serum Levels of Sex Hormone Testosterone and Bone Turnover Markers

\begin{tabular}{lccc}
\hline \hline & Testosterone $(\mathrm{ng} / \mathrm{mL})$ & TRAP $(\mathrm{U} / \mathrm{L})$ & PINP $(\mathrm{ng} / \mathrm{mL})$ \\
\hline Control & $2.07 \pm 0.38$ & $13.7 \pm 0.8$ & $303.0 \pm 24.0$ \\
Captopril & $0.78 \pm 0.10^{*}$ & $14.2 \pm 1.0$ & $263.4 \pm 11.1^{*}$ \\
\hline
\end{tabular}

Values are expressed as means \pm S.E.M., $n=7-8$ in either group. ${ }^{*} p<0.05$, versus Control group. TRAP, tartrate-resistant acid phosphatase; PINP, procollagen type I Nterminal propeptide.

A
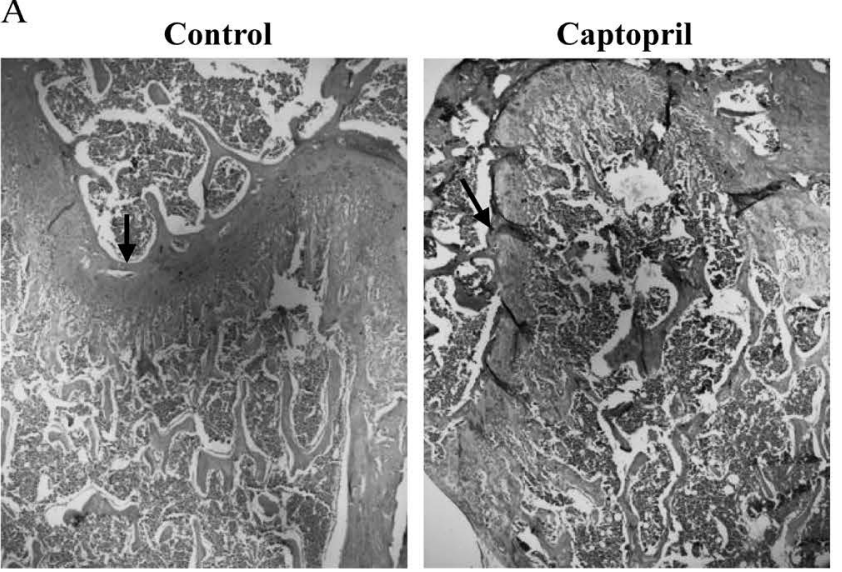

B
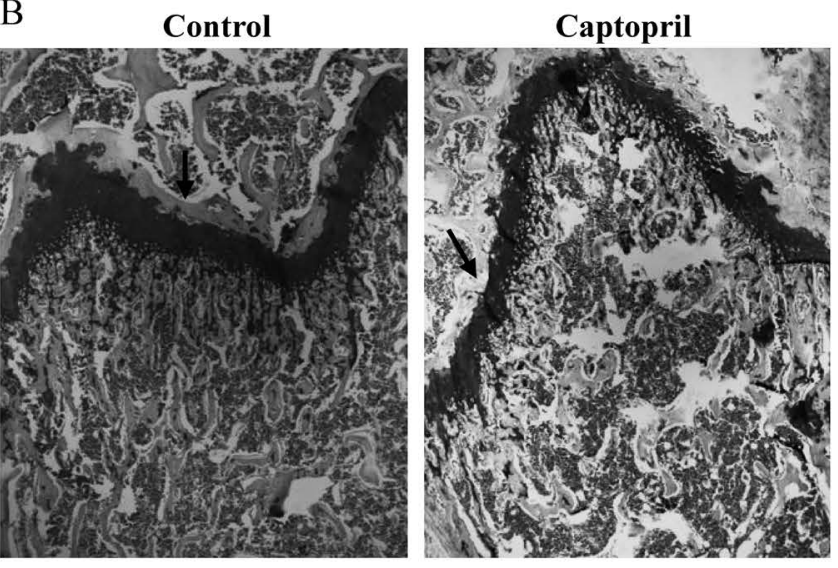

C

\section{Control}

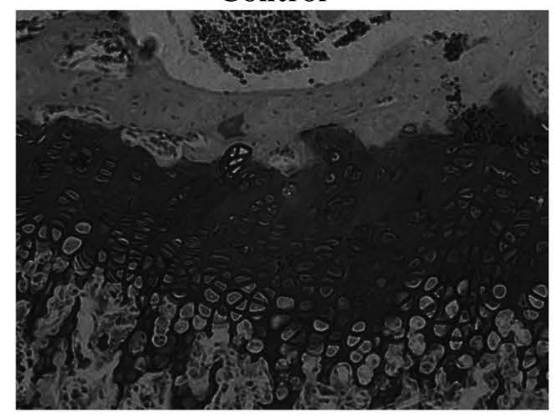

Captopril

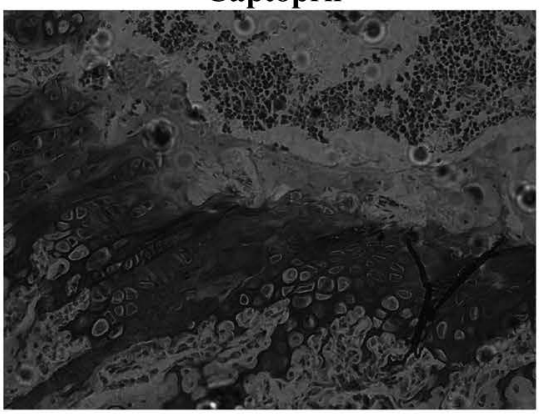

$\mathrm{D}$

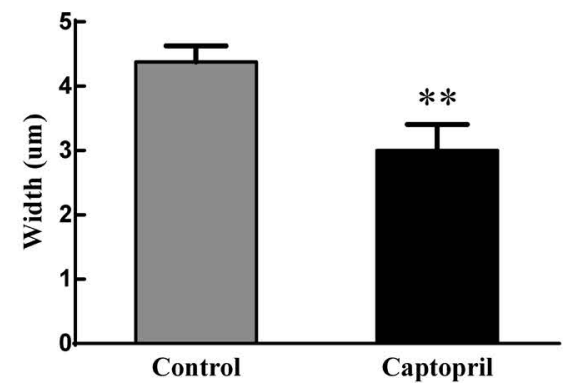

Fig. 1. Histological Images Measured by Hematoxylin \& Eosin (H\&E) Staining (A, Magnification, $\times 50$ ) and Safranin O Staining (B, Magnification, $\times 50)$ at Distal Femoral End

The cartilages adjacent to the epiphyseal plate were shown by the arrows with solid line and the interested area (B) was magnified as shown in C (magnification, $\times 200$ ), and the width of the cartilage was quantified (D). Values are expressed as means \pm S.E.M., $n=7-8 .{ }^{* *} p<0.01$, versus Control group. 
study protocol was reviewed and approved by the institution's Animal Ethics Committee at the University of Shanghai for Science and Technology.

Serum and Urine Chemistries Calcium (Ca), phosphorus $(\mathrm{P})$ and creatinine $(\mathrm{Cr})$ concentrations of serum and urine were measured by standard colorimetric methods using a micro-plate reader (Bio-Tek, U.S.A.). The level of urine $\mathrm{Ca}$ and $\mathrm{P}$ was corrected by the concentration of urine Cr. Serum levels of bone turnover markers, tartrate-resistant acid phosphatase $5 \mathrm{~b}$ (TRAP), and procollagen type I N-terminal propeptide (PINP) were determined using sandwich ELISA kit purchased from Immunodiagnostic Systems Ltd. (Boldon, U.K.). The kit for serum testosterone was provided by ALPCO (U.S.A.).

Histological Staining The femurs were fixed in $4 \%$ formaldehyde/phosphate buffered saline (PBS) ( $\mathrm{pH} 7.2)$, decalcified in $0.5 \mathrm{M}$ ethylenediaminetetraacetic acid (EDTA) ( $\mathrm{pH} 8.0)$, and embedded in paraffin by standard histological procedures. Serial sections of $3 \mu \mathrm{m}$ were cut. Safranin O (Sigma-Aldrich) staining was performed, combining with fast green and counter stain by hematoxylin. The thickness of the cartilage of the upper growth plate was measured using LAS v3.6 software coupled with a microscope (Leica DM 2500, Germany). Additionally, hematoxylin \& eosin (H\&E) and Masson-Trichrome staining were also performed, respectively. Stained slides were visualized under microscope.

Reverse Transcription Polymerase Chain Reaction (RTPCR) The tibia of each animal was crushed under liquid nitrogen condition and RNA extraction was performed according to the TRIzol manufacturer's protocol (Invitrogen, Carlsbad, California, U.S.A.). RNA integrity was verified by agarose gel electrophoresis. Synthesis of cDNAs was performed by reverse transcription reactions with $4 \mu \mathrm{g}$ of total RNA using moloney murine leukemia virus reverse transcriptase (Invitrogen, Carlsbad, California, U.S.A.) with oligo $\mathrm{dT}_{(15)}$ primers (Fermentas) as described by the manufacturer. The first strand cDNAs served as the template for the regular PCR performed using a DNA Engine (ABI). Glyceraldehyde-3-phosphate dehydrogenase (GAPDH) as an internal control was used to normalize the data to determine the relative expression of the target genes of RAS components, including AGT, ACE, renin receptor and chymase. The primer sequence for chymase as the following, Forward $\left(5^{\prime}-3^{\prime}\right)$ : TAT CCC ACC CGGGAGAAT GT; Reverse $\left(5^{\prime}-3^{\prime}\right)$ : CTGGTGAAGTGTTTGCAGGC. The PCR primers for other genes were as previously described. ${ }^{11)}$

Western Blotting The tibias were homogenized and extracted in Laemmli buffer (Boston Bioproducts, Worcester, MA, U.S.A.), followed by $5 \mathrm{~min}$ boiling and centrifugation to obtain the supernatant. Samples containing $40 \mu \mathrm{g}$ of protein were separated on $10 \%$ sodium dodecyl sulfate-polyacrylamide gel electrophoresis (SDS-PAGE) gel, transferred to nitrocellulose membranes (Bio-Rad Laboratories, Hercules, CA, U.S.A.). After saturation with $5 \%(\mathrm{w} / \mathrm{v})$ nonfat dry milk in TBS and $0.1 \%(\mathrm{w} / \mathrm{v})$ Tween 20 (TBST), the membranes were incubated with one of the following antibodies at dilutions ranging from $1: 1000$ to $1: 500$ at $4^{\circ} \mathrm{C}$ overnight: mouse antirenin monoclonal antibody, goat anti-angiotensin II polyclonal antibody, goat anti-bradykinin B1R polyclonal antibody, and goat anti-bradykinin B2R polyclonal antibody. All the above primary antibodies were purchased from Santa Cruz Biotechnology (U.S.A.). After three washes with TBST, membranes were incubated with secondary immunoglobulins conjugated to IRDye $800 \mathrm{CW}$ Infrared Dye (LI-COR), including donkey anti-goat immunoglobulin $\mathrm{G}(\mathrm{IgG})$ and donkey anti-mouse IgG with the dilution of $1: 20000$. After $2 \mathrm{~h}$-incubation at room temperature, membranes were washed three times with
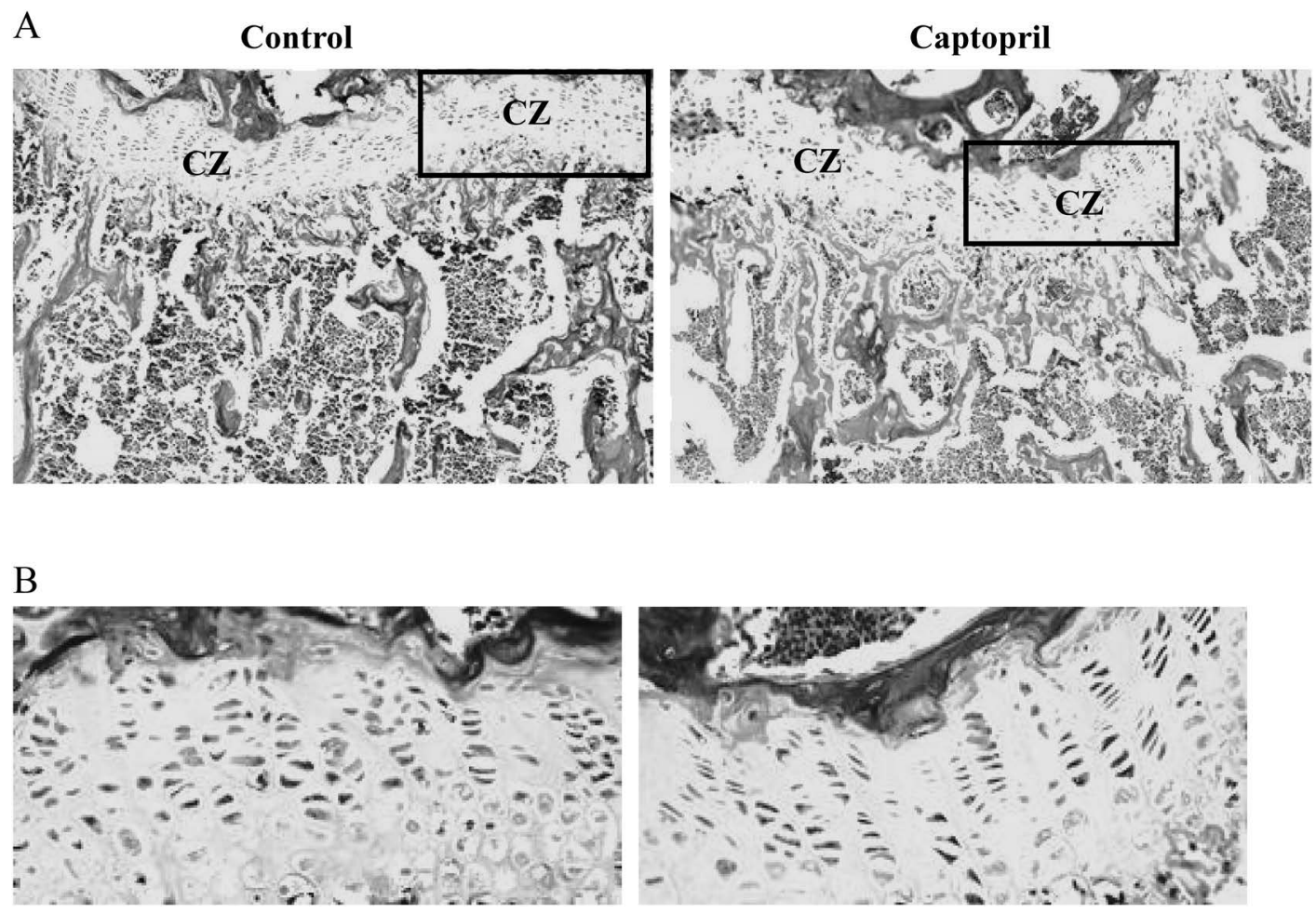

Fig. 2. Masson-Trichrome Staining of Distal Femoral End

Magnification, $\times 100$ (A). The chondrocyte zone (CZ) within the rectangle at growth plate was magnified shown as B (magnification, $\times 200$ ). 
TBST. Blots were visualized by the Odyssey Infrared Imaging System (LI-COR Biotechnology, U.S.A.). Signals were densitometrically assessed (Odyssey Application Software version 3.0) and normalized to the $\beta$-actin signals to correct for unequal loading using the mouse monoclonal anti- $\beta$-actin antibody (Sigma, U.S.A.).

Statistical Analysis The data from these experiments were reported as mean \pm standard error of the mean (S.E.M.) for each group. All statistical analyses were performed using PRISM version 4.0 (GraphPad). Inter-group differences were analyzed by one-way ANOVA, and followed by Tukey's multiple comparison test as a post test to compare the group means if overall $p<0.05$. Differences with $p$ value of less than 0.05 were considered statistically significant.

\section{RESULTS}

Serum and Urine Biomarkers The main minerals including $\mathrm{Ca}$ and $\mathrm{P}$ contained in bones were measured in serum and urine. The results (Table 1) showed that the serum and urine levels of $\mathrm{Ca}$ and $\mathrm{P}$ were comparable between the normal control group and captopril-treated group. While, the treatment with captopril decreased $(p<0.05)$ the serum level of testosterone and procollagen type I N-terminal propeptide (PINP), one of bone formation markers, as compared to those of control group (Table 2). The serum level of tartrate-resistant acid phosphatase (TRAP), one of bone resorption markers, was not changed between groups.

H\&E and Safranin O Staining H\&E staining (Fig. 1A) and Safranin $\mathrm{O}$ staining (Figs. 1B, C) were performed to observe the epiphyseal structures of distal femurs, including epiphyseal plate, upper epiphyseal cartilages and the secondary spongiosa zone. The loss of cancellous bone mass and network connections was observed at the secondary spongiosa zone of distal femurs of captopril-treated mice as compared to control mice. The thickness of cartilages adjacent to the epiphyseal plate was significantly reduced $(p<0.01)$ in distal femur of captopril group (Fig. 1D), suggesting the occurrence of delayed formation of new cartilages upper epiphyseal plate upon to captopril treatment. Both of the stainings revealed the remarkable bone abnormalities of the distal femoral end of mice administered with captopril.

Masson-Trichrome Staining The Masson-Trichrome staining was also performed on the distal end of femur (Fig. 2). The difference between groups was similar as shown by $\mathrm{H} \& \mathrm{E}$ and Safranin O staining (Fig. 2A). The chondrocyte zone at growth plate was magnified to observe the proliferation zone and hypertrophic zone (Fig. 2B). The cell in proliferation zone was markedly compressed in the captopril group. The number of chondrocyte in the captopril-treated group in the hypertrophic zone of growth plate was significantly smaller than that of the control group.

mRNA Expression of Skeletal RAS Components The mRNA expression of RAS components, including angiotensinogen (AGT), ACE, and renin receptor was measured in tibia (Fig. 3). The treatment of captopril significantly increased the mRNA expression of renin receptor (Fig. $3 \mathrm{C}, p<0.01$ ), but did not change the mRNA expression of AGT or chymase. The mRNA expression of ACE upon to captopril treatment for 4 weeks and 8 weeks was increased by $38 \%$ (Fig. 3D, $p<0.05$ ) and $21 \%$, respectively, as compared to those of control group.
Protein Expression of Skeletal RAS Components The protein expression of renin, Ang II, bradykinin B1 receptor (B1R) and B2 receptor (B2R) was determined in tibia (Fig. 4). The mice after treatment with captopril showed higher expression of Ang II (Fig. 4B, $p<0.05)$ and B2R $(p<0.05)$ than those of mice without treatment. In addition, the captopril treatment did not alter the protein expression of renin and B1R.

\section{DISCUSSION}

Several studies have suggested that high blood pressure is
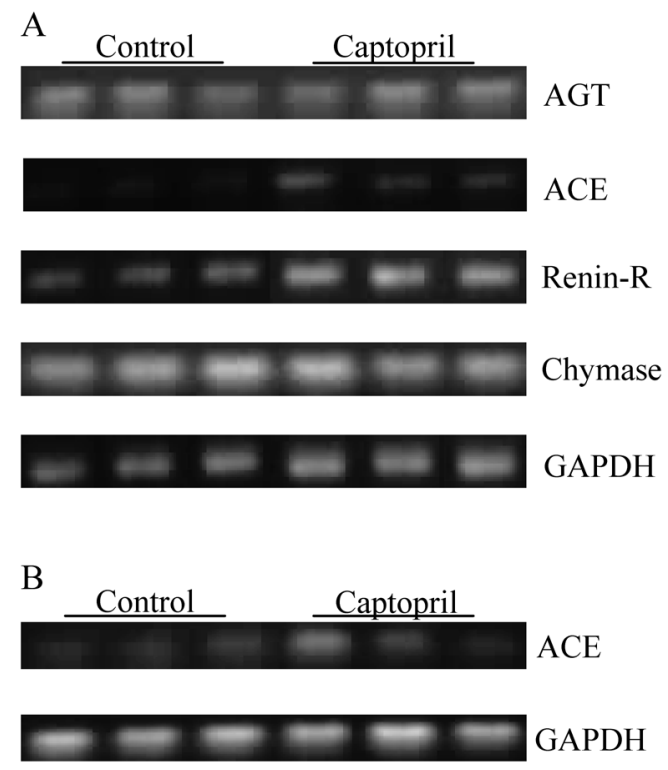

C

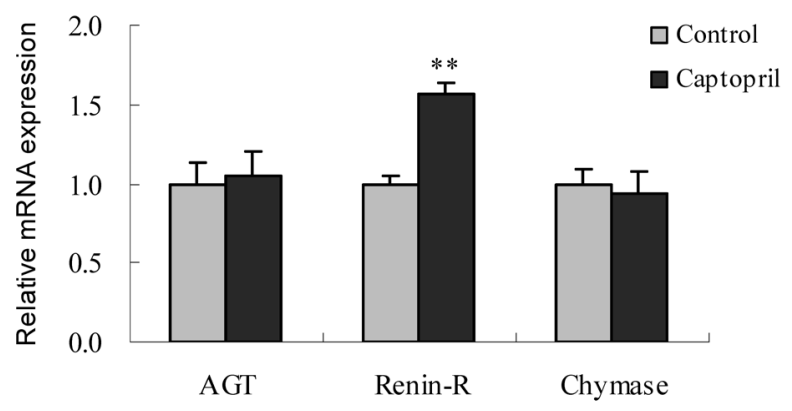

$\mathrm{D}$

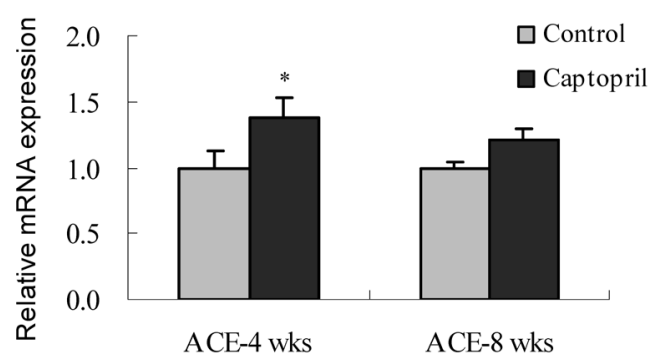

Fig. 3. mRNA Expression of RAS Components in Tibia (A, B), and the Densitometric Quantification of the mRNA Expression Levels, Which Are Expressed as a Ratio to the Expression of GAPDH (C, D)

A, treatment with captopril for 4 weeks $(4 \mathrm{wks})$; B, treatment with captopril for 8 weeks $(8 \mathrm{wks})$. AGT, angiotensinogen; ACE, angiotensin-converting enzyme; Renin-R, renin receptor. Values are expressed as means \pm S.E.M., $n=7-8 .{ }^{*} p<0.05$, $* * p<0.01$ versus Control group. 


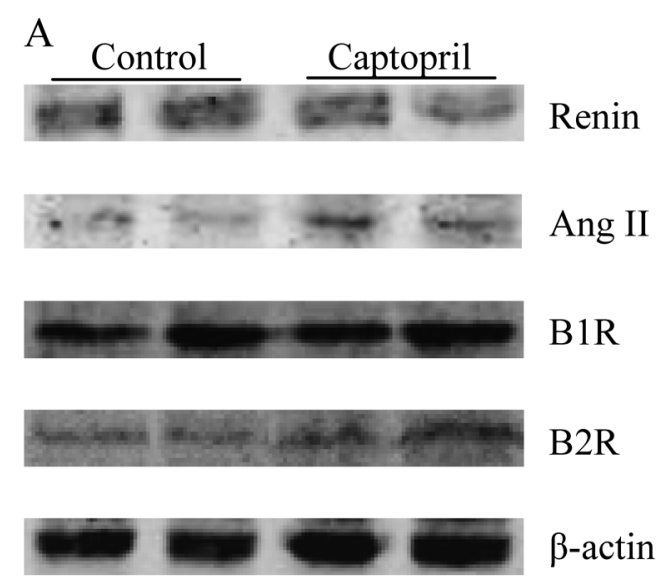

B

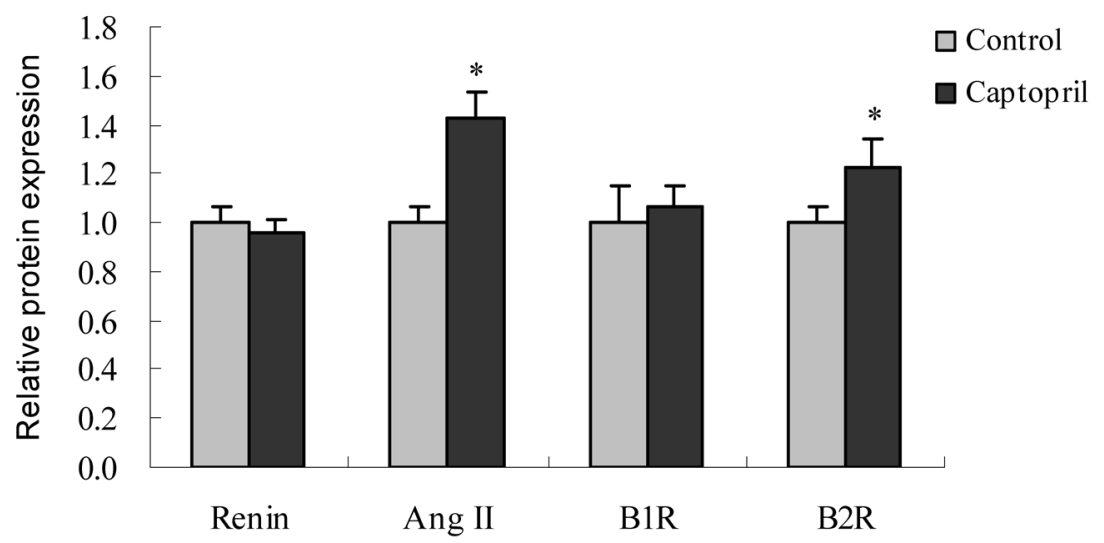

Fig. 4. Protein Expression of Renin, Angiotensin II (Ang II) and Bradykinin Receptors in Tibia (A) and the Densitometric Quantification of the Protein Expression Levels, Which Are Expressed as a Ratio to the Expression of $\beta$-Actin (B)

Values are expressed as means \pm S.E.M., $n=7-8 . * p<0.05$ versus Control group.

associated with the risk of bone loss. ${ }^{25)}$ Thus, closer attention should be paid to the effects of agents used in the treatment of cardiac-vascular diseases (CVD) on bone mass and possible intervention approaches. Additionally, ACEIs are currently in wide use for the treatment of diabetes complications, like diabetes-induced heart diseases ${ }^{26)}$ and diabetes nephropathy, ${ }^{27)}$ moreover, osteoporosis is often associated with diabetes. ${ }^{28)}$ Therefore, it is important to clarify the influences of ACEIs on bone metabolism. In this study, we investigated the effects of one classical ACEI, captopril, on bone turnover, bone histology, skeletal RAS and bradykinin receptors.

Previously, most of clinical studies demonstrated that patients treated with ACEI showed an increased BMD and a reduced fracture risk. ${ }^{18,19,29)}$ The treatment of Tsukuba hypertensive mouse with enalapril improved osteoporosis ${ }^{7}$ as well as the ovariectomized rats in response to the treatment with ACEI captopril ( 1 or $5 \mathrm{mg} / \mathrm{kg}$ ) showed the increased trabecular area of lumbar vertebrae (L4) and the improved biomechanical properties by increasing L5 break stress and elastic modulus. ${ }^{16)}$ While, we showed in this study that captopril, which inhibits the conversion of Ang I to the active hormone Ang II, has the potential effects of damaging the micro-architecture of trabecular bone and destroying the chondrocyte zone of epiphyseal plate in normal male mice.

The impairments of captopril on trabecular bone are surprising, since ACE is the major enzyme producing Ang II. A possible reason may be the effects of ACE inhibitors on sex hormones. This study found that captopril decreased the circulating level of testosterone in male mice, in accordance with previous report that lisinopril significantly decreased free testosterone in men and increased sex hormone-binding globulin in women over a 6-month period. ${ }^{30)}$ The mechanisms have still not been fully demonstrated and more research needs to be carried out to clarify the relationship between the RAS and sex hormones. In addition, a cross-sectional study of older Chinese men, found that ACE inhibitor use was associated with lower serum dehydroepiandrosterone. ${ }^{31)}$

It is well known that the high activity of skeletal RAS, especially the increased production of Ang II, the bioactive peptide within RAS, would lead to bone injuries. This study showed that captopril induced the up-regulation of the expression of ACE, Ang II and renin receptor in bone of mice, suggesting the classical pathway of RAS, so-called ACE/Ang II/Ang II receptors, and the pathway of renin with renin receptor were both activated in mice bone in response to ACEI. The present study demonstrated the upregulation of 
ACE mRNA expression by $38 \%$ and $21 \%$ in tibia of mice after captopril treatment for 4 weeks and 8 weeks, in accordance with the earlier in vivo study which suggested that the treatment with ACE inhibitor perindopril for 2 and 4 weeks was able to upregulate ACE2 expression under conditions of liver injury, ${ }^{32)}$ while, the mechanisms on the upregulation of $\mathrm{ACE}$ inhibitors on either ACE or ACE2 in tissues are not clearly known yet, moreover, the long-term effect of ACE inhibitors on tissue ACE expression need to be further clarified. Besides ACE, chymase could also cleave Ang I to generate Ang II, ${ }^{33)}$ while, this study showed that chymase was not involved in the effects of ACEI on bones.

Although short-term ACEI therapy was associated with decreased Ang II level, there were some evidences that longterm ACE inhibition resulted in a return of Ang II towards baseline level, so-called 'ACE escape.'22) In addition, the common problem for RAS inhibitor is the appearance of a compensatory increase of local RAS activity after drug use as shown in this study. This increase in RAS activity stimulates the conversion of Ang I and ultimately Ang II, leading to reduction in the efficacy of RAS inhibition.,4)

Another possible reason may be that ACE inhibitors act not only on the RAS, but also on the kinin-kallikrein system by suppressing degradation of bradykinin, ${ }^{22)}$ which is the major effector peptide of the kallikrein-kinin system and is regulated by angiotensin-converting enzyme, which degrades the peptide. Bradykinin normally exerts its effects through the activation of two seven transmembrane $G$ protein-coupled receptors, named B1 and B2. It was reported that bradykinin can decrease the differentiation of osteoblasts with concomitant increase in osteoclast formation, consequently stimulating bone resorption and reduce $\mathrm{BMD},{ }^{34-36)}$ and that the lack of both $\mathrm{B} 1 \mathrm{R}$ and $\mathrm{B} 2 \mathrm{R}$ accelerated the loss of bone minerals. ${ }^{37)}$ The present study showed that captopril induced the up-regulation of $\mathrm{B} 2 \mathrm{R}$ protein expression, indicating the use of captopril might enhance the B2R-involved signals of bradykinin in bone, thereafter impairing bone metabolism. While the underlying mechanism of the modulation of ACEI on bradykinin receptor need to be further elucidated.

Taken together, the present study demonstrated that the treatment with ACEI captopril has detrimental effects on trabecular bone of normal mice. The potential underlying mechanism for the damages of captopril on bone may be attributed to the increased activity of local bone RAS and the activation of bradykinin receptor upon to captopril treatment. More research needs to be carried out to clarify the influence of the ACEI treatment on bone health as this might be of clinical relevance when antihypertensive therapy is initiated, particularly in hypertensive women who typically suffer from a concomitant rapid onset of osteoporosis after menopause.

Acknowledgments This work was sponsored by National Natural Science Foundation of China (No. 81202894) and Shanghai Pujiang Program (10PJ1407700).

Conflict of Interest The authors declare no conflict of interest.

\section{REFERENCES}

1) Namazi S, Ardeshir-Rouhani-Fard S, Abedtash H. The effect of renin angiotensin system on tamoxifen resistance. Med. Hypotheses, 77, 152-155 (2011)

2) Lau T, Carlsson PO, Leung PS. Evidence for a local angiotensingenerating system and dose-dependent inhibition of glucose-stimulated insulin release by angiotensin II in isolated pancreatic islets. Diabetologia, 47, 240-248 (2004).

3) Zhang Z, Zhang Y, Ning G, Deb DK, Kong J, Li YC. Combination therapy with AT1 receptor blocker and vitamin D analog markedly ameliorates diabetic nephropathy: blockade of compensatory renin increase. Proc. Natl. Acad. Sci. U.S.A., 105, 15896-15901 (2008).

4) Zhang Y, Deb DK, Kong J, Ning G, Wang Y, Li G, Chen Y, Zhang Z, Strugnell S, Sabbagh Y, Arbeeny C, Li YC. Long-term therapeutic effect of vitamin D analog doxercalciferol on diabetic nephropathy: strong synergism with AT1 receptor antagonist. Am. J. Physiol. Renal Physiol., 297, F791-F801 (2009).

5) Koïtka A, Cao Z, Koh P, Watson AMD, Sourris KC, Loufrani L, Soro-Paavonen A, Walther T, Woollard KJ, Jandeleit-Dahm KA, Cooper ME, Allen TJ. Angiotensin II subtype 2 receptor blockade and deficiency attenuate the development of atherosclerosis in an apolipoprotein E-deficient mouse model of diabetes. Diabetologia, 53, 584-592 (2010).

6) Inaba S, Iwai M, Furuno M, Kanno H, Senba I, Okayama H, Mogi M, Higaki J, Horiuchi M. Role of angiotensin-converting enzyme 2 in cardiac hypertrophy induced by nitric oxide synthase inhibition. J. Hypertens., 29, 2236-2245 (2011).

7) Asaba $Y$, Ito $M$, Fumoto $T$, Watanabe $K$, Fukuhara $R$, Takeshita S, Nimura Y, Ishida J, Fukamizu A, Ikeda K. Activation of reninangiotensin system induces osteoporosis independently of hypertension. J. Bone Miner. Res., 24, 241-250 (2009).

8) Izu Y, Mizoguchi F, Kawamata A, Hayata T, Nakamoto T, Nakashima K, Inagami T, Ezura Y, Noda M. Angiotensin II type 2 receptor blockade increases bone mass. J. Biol. Chem., 284, 4857-4864 (2009).

9) Yongtao Z, Kunzheng W, Jingjing Z, Hu S, Jianqiang K, Ruiyu L, Chunsheng W. Glucocorticoids activate the local renin-angiotensin system in bone: possible mechanism for glucocorticoid-induced osteoporosis. Endocrine, 47, 598-608 (2014).

10) Zhang Y, Wang K, Song Q, Liu R, Ji W, Ji L, Wang C. Role of the local bone renin-angiotensin system in steroid-induced osteonecrosis in rabbits. Mol. Med. Rep., 9, 1128-1134 (2014).

11) Gu SS, Zhang Y, Li XL, Wu SY, Diao TY, Hai R, Deng H. Involvement of the skeletal renin-angiotensin system in age-related osteoporosis of ageing mice. Biosci. Biotechnol. Biochem., 76, 1367-1371 (2012).

12) Gu SS, Zhang Y, Wu SY, Diao TY, Gebru YA, Deng H. Early molecular responses of bone to obstructive nephropathy induced by unilateral ureteral obstruction in mice. Nephrology, 17, 767-773 (2012).

13) Diao TY, Pan H, Gu SS, Chen X, Zhang FY, Wong MS, Zhang Y. Effects of angiotensin-converting enzyme inhibitor, captopril, on bone of mice with streptozotocin-induced type 1 diabetes. J. Bone Miner. Metab., 32, 261-270 (2014).

14) Garcia P, Schwenzer S, Slotta JE, Scheuer C, Tami AE, Holstein JH, Histing T, Burkhardt M, Pohlemann T, Menger MD. Inhibition of angiotensin-converting enzyme stimulates fracture healing and periosteal callus formation-role of a local renin-angiotensin system. Br. J. Pharmacol., 159, 1672-1680 (2010).

15) Shimizu H, Nakagami H, Osako MK, Hanayama R, Kunugiza Y, Kizawa T, Tomita T, Yoshikawa H, Ogihara T, Morishita R. Angiotensin II accelerates osteoporosis by activating osteoclasts. FASEB J., 22, 2465-2475 (2008).

16) Liu YY, Yao WM, Wu T, Xu BL, Chen F, Cui L. Captopril improves osteopenia in ovariectomized rats and promotes bone formation in osteoblasts. J. Bone Miner. Metab., 29, 149-158 (2011).

17) Lynn H, Kwok T, Wong SY, Woo J, Leung PC. Angiotensin converting enzyme inhibitor use is associated with higher bone mineral 
density in elderly Chinese. Bone, 38, 584-588 (2006).

18) García-Testal A, Monzó A, Rabanaque G, González A, Romeu A. Evolution of the bone mass of hypertense menopausal women in treatment with fosinopril. Med. Clin. (Barc.), 127, 692-694 (2006).

19) Rejnmark L, Vestergaard P, Mosekilde L. Treatment with betablockers, ACE inhibitors, and calcium-channel blockers is associated with a reduced fracture risk: a nationwide case-control study. J. Hypertens., 24, 581-589 (2006).

20) Stimpel M, Ma Y, Yamamoto N, Chen Y. Impact of antihypertensive therapy on postmenopausal osteoporosis: effects of the angiotensin converting enzyme inhibitor moexipril, 17beta-estradiol and their combination on the ovariectomy-induced cancellous bone loss in young rats. J. Hypertens., 13, 1852-1856 (1995).

21) Kwok T, Leung J, Zhang YF, Bauer D, Ensrud KE, Barrett-Connor E, Leung PC, Osteoporotic Fractures in Men (MrOS) Research Group. Does the use of ACE inhibitors or angiotensin receptor blockers affect bone loss in older men? Osteoporos. Int., 23, 21592167 (2012).

22) Zhang YF, Qin L, Leung PC, Kwok TC. The effect of angiotensinconverting enzyme inhibitor use on bone loss in elderly Chinese. $J$. Bone Miner. Metab., 30, 666-673 (2012).

23) Masunari N, Fujiwara S, Nakata Y, Furukawa K, Kasagi F. Effect of angiotensin converting enzyme inhibitor and benzodiazepine intake on bone loss in older Japanese. Hiroshima J. Med. Sci., 57, 17-25 (2008).

24) Shimizu H, Nakagami H, Osako MK, Nakagami F, Kunugiza $Y$, Tomita T, Yoshikawa H, Rakugi H, Ogihara T, Morishita R. Prevention of osteoporosis by angiotensin-converting enzyme inhibitor in spontaneous hypertensive rats. Hypertens. Res., 32, 786-790 (2009).

25) Cappuccio FP, Meilahn E, Zmuda JM, Cauley JA. High blood pressure and bone-mineral loss in elderly white women: a prospective study. Study of Osteoporotic Fractures Research Group. Lancet, 354, 971-975 (1999).

26) Cheng J, Zhang W, Zhang X, Han F, Li X, He X, Li Q, Chen J. Effect of angiotensin-converting enzyme inhibitors and angiotensin II receptor blockers on all-cause mortality, cardiovascular deaths, and cardiovascular events in patients with diabetes mellitus: a metaanalysis. JAMA Intern. Med., 174, 773-785 (2014).

27) Impellizzeri D, Esposito E, Attley J, Cuzzocrea S. Targeting inflammation: new therapeutic approaches in chronic kidney disease
(CKD). Pharmacol. Res., 81, 91-102 (2014).

28) Hofbauer LC, Brueck CC, Singh SK, Dobnig H. Osteoporosis in patients with diabetes mellitus. J. Bone Miner. Res., 22, 1317-1328 (2007).

29) Ghosh M, Majumdar SR. Antihypertensive medications, bone mineral density, and fractures: a review of old cardiac drugs that provides new insights into osteoporosis. Endocrine, 46, 397-405 (2014).

30) Koshida H, Takeda R, Miyamori I. Lisinopril decreases plasma free testosterone in male hypertensive patients and increases sex hormone binding globulin in female hypertensive patients. Hypertens. Res., 21, 279-282 (1998).

31) Kwok T, Ohlsson C, Vandenput L, Tang N, Zhang YF, Tomlinson B, Leung PC. ACE inhibitor use was associated with lower serum dehydroepiandrosterone concentrations in older men. Clin. Chim. Acta, 411, 1122-1125 (2010).

32) Huang ML, Li X, Meng Y, Xiao B, Ma Q, Ying SS, Wu PS, Zhang ZS. Upregulation of angiotensin-converting enzyme (ACE) 2 in hepatic fibrosis by ACE inhibitors. Clin. Exp. Pharmacol. Physiol., 37, e1-e6 (2010).

33) Passos-Silva DG, Verano-Braga T, Santos RA. Angiotensin-(1-7): beyond the cardio-renal actions. Clin. Sci., 124, 443-456 (2013).

34) Souza PP, Brechter AB, Reis RI, Costa CA, Lundberg P, Lerner UH. IL-4 and IL-13 inhibit IL- $\beta$ and TNF- $\alpha$ induced kinin B1 and B2 receptors through a STAT6-dependent mechanism. Br. J. Pharmacol., 169, 400-412 (2013).

35) Srivastava S, Sharma K, Kumar N, Roy P. Bradykinin regulates osteoblast differentiation by $\mathrm{Akt} / \mathrm{ERK} / \mathrm{NF} \kappa \mathrm{B}$ signaling axis. J. Cell. Physiol., 229, 2088-2105 (2014).

36) Gonçalves-Zillo TO, Pugliese LS, Sales VMT, Mori MA, SquaiellaBaptistão CC, Longo-Maugéri IM, Lopes JD, de Oliveira SM, Monteiro AC, Pesquero JB. Increased bone loss and amount of osteoclasts in kinin B1 receptor knockout mice. J. Clin. Periodontol., 40, 653-660 (2013).

37) Kakoki M, Sullivan KA, Backus C, Hayes JM, Oh SS, Hua K, Gasim AM, Tomita H, Grant R, Nossov SB, Kim HS, Jennette JC, Feldman EL, Smithies O. Lack of both bradykinin B1 and B2 receptors enhances nephropathy, neuropathy, and bone mineral loss in Akita diabetic mice. Proc. Natl. Acad. Sci. U.S.A., 107, 1019010195 (2010). 